\title{
Gadolinium-based hybrid nanoparticles as a positive MR contrast agent
}

\author{
Hiroki Hifumi,${ }^{\dagger}$ Seiichi Yamaoka,${ }^{\dagger}$ Akihiro Tanimoto,${ }^{\dagger}$ Daniel Citterio, ${ }^{\dagger}$ and Koji Suzuki ${ }^{*}$ \\ $\dagger, \ddagger$ \\ Contribution from Department of Applied Chemistry, Faculty of Science and Technology, Keio \\ University, 3-14-1 Hiyoshi, Hokoku-ku, Yokohama 223-8522, Japan, and Core Research for \\ Evolutional Science and Technology (CREST), JST Agency, 4-1-8 Honcho, Kawaguchi, Saitama \\ 332-0012, Japan
}

\section{Supporting Information}

\section{Materials and Instrumentation.}

Gadolinium(III) nitrate hexahydrate $\left(\mathrm{Gd}\left(\mathrm{NO}_{3}\right)_{3} \bullet 6 \mathrm{H}_{2} \mathrm{O}\right)$, ammonium hydrogenphosphate $\left(\left(\mathrm{NH}_{4}\right)_{2} \mathrm{HPO}_{4}\right)$, and xylenol orange were purchased from the Sigma-Aldrich Chemical Co. (St. Louis, MO). Dextran-40,000, sodium hydroxide $(\mathrm{NaOH})$, and nitric acid $\left(\mathrm{HNO}_{3}\right)$ were purchased from the Wako Pure Chemical Industries, Ltd. (Osaka, Japan). Magnevist ${ }^{\circledR}$ and Resovist ${ }^{\circledR}$ were obtained from Nihon Schering K.K. (Osaka, Japan). All materials were used without further purification.

Centrifugation was performed using an Allegra 21R Centrifuge of the Beckman Coulter K. K. (Tokyo, Japan). The gadolinium concentration was determined using an inductively coupled plasma atomic emission spectrometer (ICP-AES) ICPS-8000 of the Shimadzu Co. (Kyoto, Japan). Transmission electron microscopy (TEM) was performed using a TECNAI F20 at $200 \mathrm{kV}$ and a TECNAI 12 at $120 \mathrm{kV}$ from the FEI Company Japan, Ltd. (Tokyo, Japan). For the TEM sample preparation, the particle solution was deposited on a carbon-coated copper grid and allowed to air-dry. The powder X-ray diffractometry (XRD) patterns were obtained using $\mathrm{Cu} \mathrm{K} \alpha$ radiation with a MPX-3A from MAC Science and D8 ADVANCE from the Bruker AXS K.K. (Ibaraki, Japan). To obtain samples in powder form, the solvent was removed under reduced pressure. Dynamic light scattering (DLS) measurements were performed using an ELS-8000 from Otsuka Electronics (Osaka, Japan) at a $90^{\circ}$ scattering angle for optimum detection. A satisfactory intensity was obtained by diluting a solution of PGP/dextran-K01 with distilled water. The fourier transform infrared (FT-IR) spectra of the prepared solid samples in $\mathrm{KBr}$ pellets were recorded in the range between 500 and 4000 $\mathrm{cm}^{-1}$ on a FT/IR-600 plus from the JASCO (Tokyo, Japan). The longitudinal and transverse relaxation times were measured in distilled water on a 0.47 T NMS 120 Minispec NMR ANALYZER from the Bruker Optics K.K. (Ibaraki, Japan) at $40^{\circ} \mathrm{C}$. The MR images were obtained using a SIGNA EXCITE XI 1.5 T from the GE Healthcare (Tokyo, Japan). The measurement conditions were as follows: $T_{1}$-weighted sequence: Spin echo, ET $=1 \mathrm{~ms}, \mathrm{Tr} / \mathrm{Te}=300.0 / 8.0 \mathrm{~ms}$, Matrix $256 \times 256, \mathrm{NEX}=2$, FOV $=18.0 \times 18.0 \mathrm{~cm}$, slice thickness $=7.0 \mathrm{~mm} ; T_{2}$-weighted sequence $($ Fast $)$ Spin echo, ET $=16 \mathrm{~ms}$,

$\mathrm{Tr} / \mathrm{Te}=3000.0 / 16.1 \mathrm{~ms}$, Matrix $256 \times 256, \mathrm{NEX}=2, \mathrm{FOV}=18.0 \times 18.0 \mathrm{~cm}$, slice thickness $=7.0 \mathrm{~mm}$. 
The magnetization of the PGP/dextran-K01 was measured by a $7 \mathrm{~T}$ Quantum Design SQUID magnetometer of the Quantum Design Japan (Tokyo, Japan) at $300 \mathrm{~K}$. Absorbance spectra for the free $\mathrm{Gd}^{3+}$ leaching study were measured on a U-2001 spectrophotometer from the Hitachi (Tokyo, Japan).

\section{Theory of relaxivity of a solution. ${ }^{1}$}

The presence of a paramagnetic species $(M)$ in solution causes a decrease in the longitudinal and transverse relaxation times of the solvent, $T_{1}$ and $T_{2}$, respectively. The decrease in the relaxation time is linearly dependent on the concentration of the paramagnetic species $([M])$; the relaxivity $r_{\mathrm{n}}$ is defined as the slope of this dependence in units of $\sec ^{-1}$ per $\mathrm{mM}$ of $M$.

$$
r_{i}=\frac{\left(\frac{1}{T_{i}}\right)_{o b s d}-\left(\frac{1}{T_{i}}\right)_{d}}{[M]} \quad(i=1,2)
$$

where $\left(1 / T_{\mathrm{i}}\right)_{\mathrm{d}}$ is the inverse of the (diamagnetic) solvent relaxation time in the absence of a paramagnetic species and $\left(1 / T_{\mathrm{i}}\right)_{\text {obsd }}$ is the inverse of the observed solvent relaxation time in the presence of a paramagnetic species.

\section{Synthesis of PGP/dextran-K01.}

$\mathrm{Gd}\left(\mathrm{NO}_{3}\right)_{3} \bullet 6 \mathrm{H}_{2} \mathrm{O}(0.675 \mathrm{~g} ; 1.50 \mathrm{mmol})$ was dissolved in distilled water $(5 \mathrm{~mL})$ and poured into a 1 $\mathrm{M}$ aqueous $\mathrm{NaOH}$ solution $(5 \mathrm{~mL})$. A solution of $\left(\mathrm{NH}_{4}\right)_{2} \mathrm{HPO}_{4}(0.178 \mathrm{~g} ; 1.35 \mathrm{mmol})$ in distilled water (5 mL) and Dextran-40,000 (3.90g) were then added. The mixture was adjusted to $\mathrm{pH} 12.5$ with a $4 \mathrm{M}$ aqueous $\mathrm{NaOH}$ solution and poured into a glass pressure tube equipped with a magnetic stirring bar. The tube was capped and subsequently heated to $200{ }^{\circ} \mathrm{C}$ for $2 \mathrm{~h}$ with stirring at $600 \mathrm{rpm}$. The resulting suspension was centrifuged at $3200 \mathrm{rpm}$ for $10 \mathrm{~min}$ and the supernatant was discarded. In order to remove the $\mathrm{Gd}(\mathrm{OH})_{3}$ formed as a byproduct, excess dextran and other impurities, the precipitate was suspended in $0.1 \mathrm{M} \mathrm{HNO}_{3}(30 \mathrm{~mL})$ and stirred for 1 day while keeping the $\mathrm{pH}$ at 1 with $1 \mathrm{M} \mathrm{HNO}_{3}$. The suspension was centrifuged at $3200 \mathrm{rpm}$ for $5 \mathrm{~min}$, and the supernatant was discarded. The precipitate was added to distilled water $(20 \mathrm{~mL})$ and stirred for $30 \mathrm{~min}$. The suspension was then centrifuged at $3200 \mathrm{rpm}$ for $5 \mathrm{~min}$ and the corn-colored supernatant was decanted. This step was repeated 4 times. Finally, the combined supernatants were centrifuged at $5500 \mathrm{rpm}$ for $20 \mathrm{~min}$, and the corn-colored supernatant was decanted. 


\section{Powder XRD patterns.}

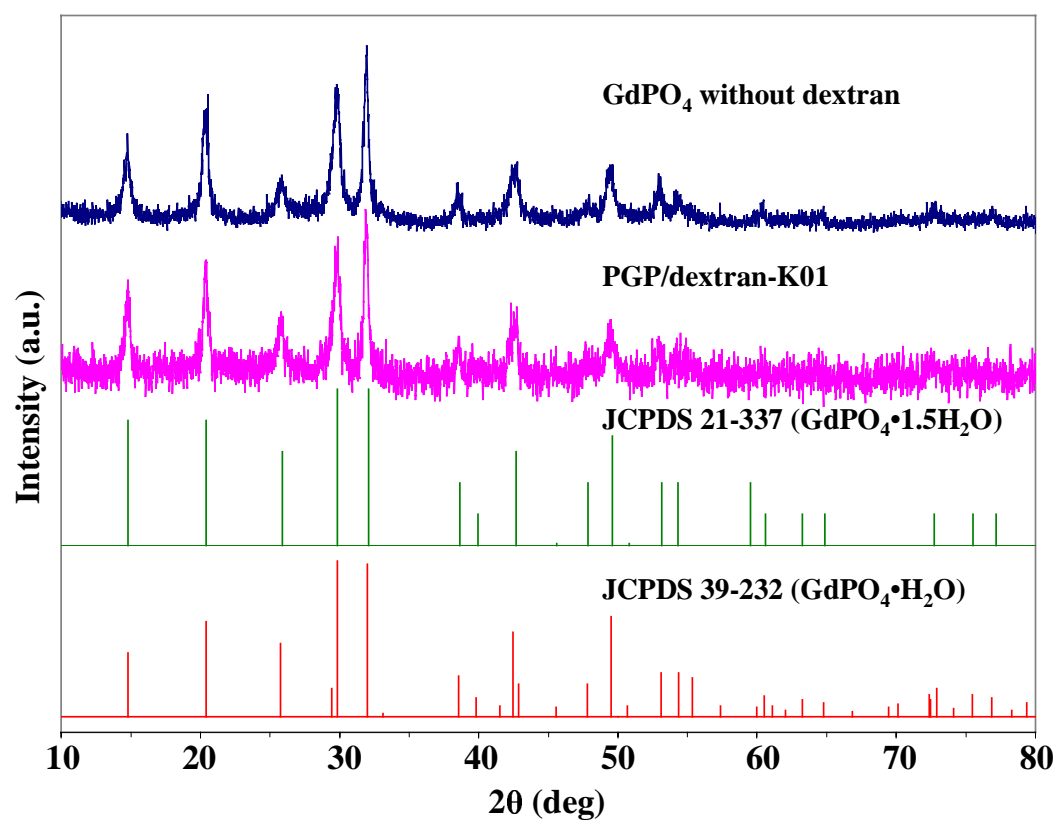

Figure S1. Powder XRD patterns of $\mathrm{GdPO}_{4}$ without dextran (first row), PGP/dextran-K01 (second row), and JCPDS files of $\mathrm{GdPO}_{4} \bullet 1.5 \mathrm{H}_{2} \mathrm{O}$ (third row) and $\mathrm{GdPO}_{4} \bullet \mathrm{H}_{2} \mathrm{O}$ (fourth row).

\section{DLS measurement.}

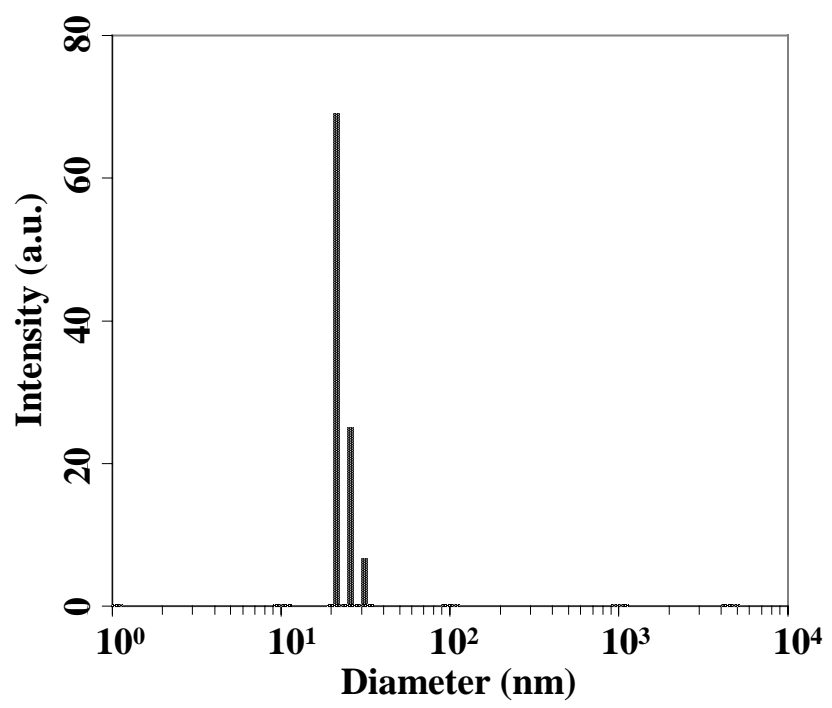

Figure S2. DLS measurement of PGP/dextran-K01 in distilled water at $25.2^{\circ} \mathrm{C}$. 


\section{FT-IR measurements.}

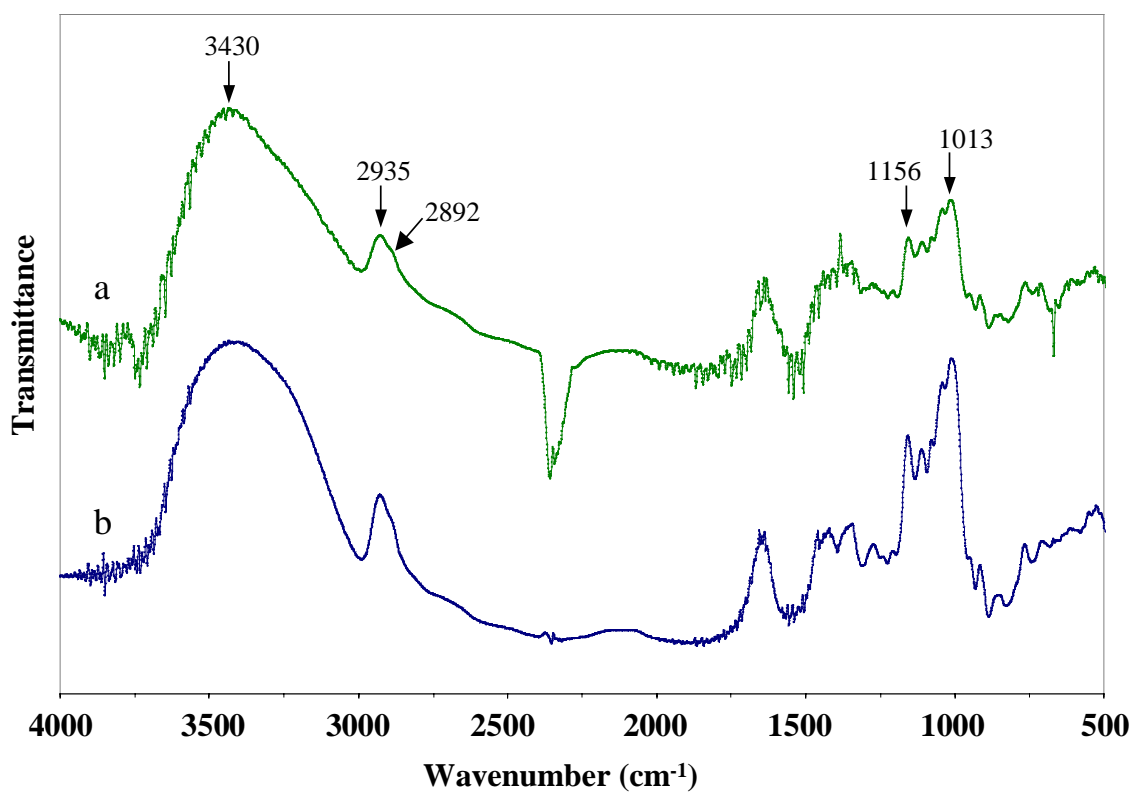

Figure S3. FT-IR spectra of (a) PGP/dextran-K01 (top) powdered by solvent evaporation and (b) dextran (bottom); spectra recorded in $\mathrm{KBr}$ pellets.

\section{Relaxivity measurements.}

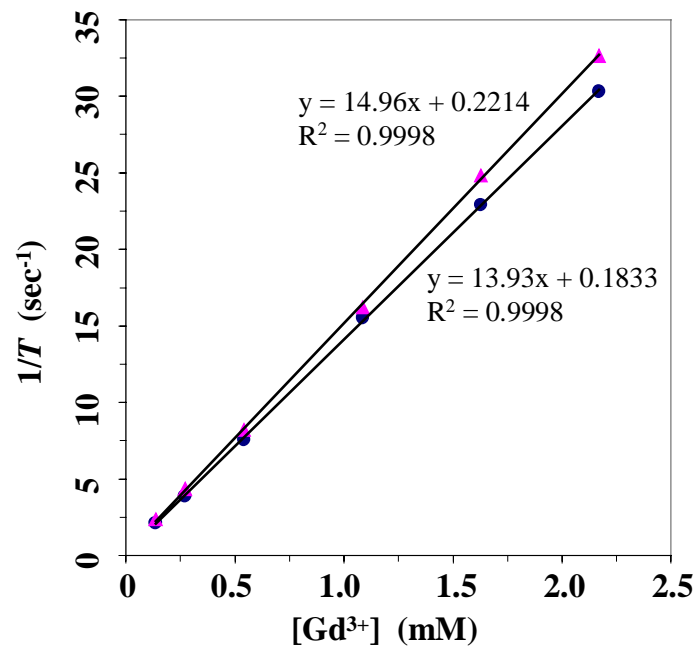

Figure S4. The $r_{1}$ (circle) and $r_{2}$ (triangle) relaxivity curves were obtained from solutions of various PGP/dextran-K01 concentrations. 


\section{SQUID measurement.}

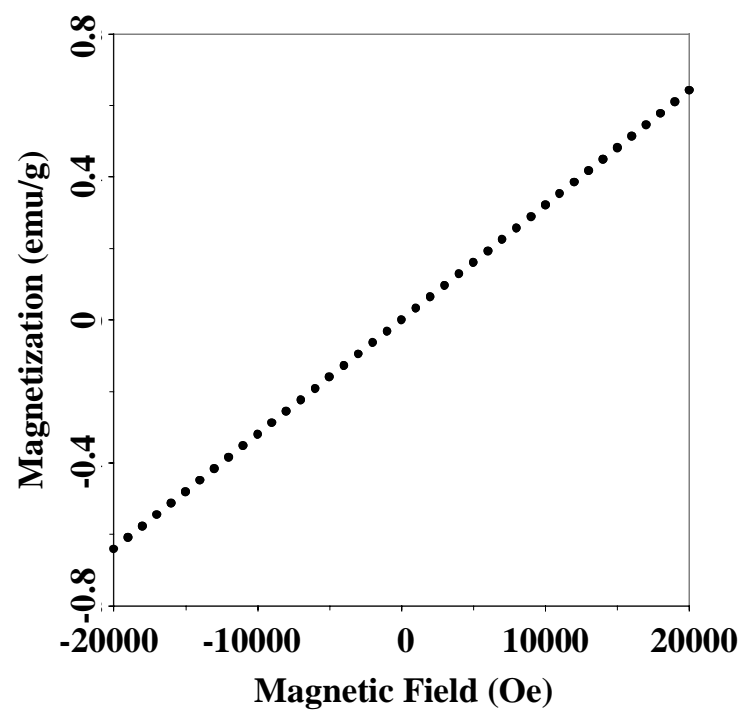

Figure S5. Magnetization curve of PGP/dextran-K01 at $300 \mathrm{~K}$.

\section{Leaching study of free $\mathrm{Gd}^{3+}$.}

Due to the high toxicity of free $\mathrm{Gd}^{3+}$ ions, an aqueous dispersion of PGP/dextran-K01 nanoparticles $\left(2.2 \mathrm{mM}\right.$ of $\left.\mathrm{Gd}^{3+}\right)$ stored at $4{ }^{\circ} \mathrm{C}$ for 2 weeks was examined for the presence of free $\mathrm{Gd}^{3+}$ possibly leaching out from the nanoparticles. For this purpose, xylenol orange was used as a sensitive indicator for the detection of free $\mathrm{Gd}^{3+}$ ions in a 10-fold diluted sample. ${ }^{2}$

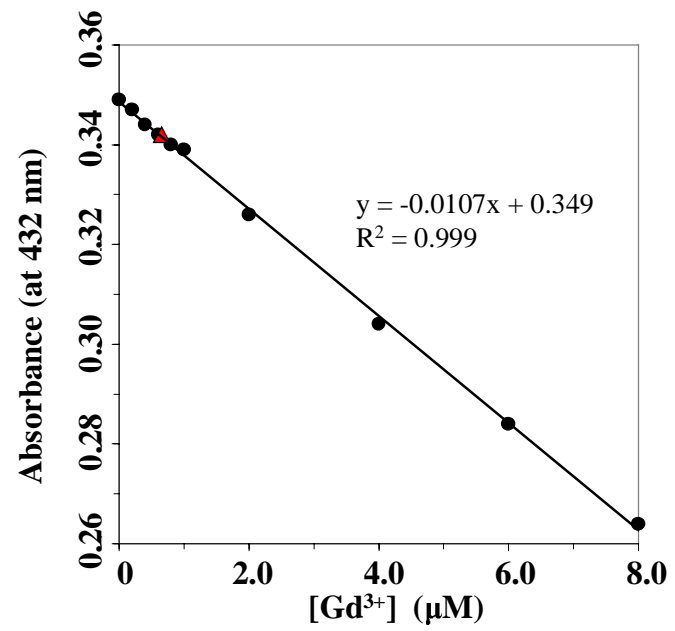

Figure S6. Calibration curve for $\mathrm{Gd}^{3+}$ in aqueous solution: aqueous calibration samples (circles); PGP/dextran-K01 dispersion 10-fold diluted (triangle); [xylenol orange] $=18.0 \mu \mathrm{M}$. 
From the data in Figure S6, a very low concentration of free $\mathrm{Gd}^{3+}$ ions of $6.54 \mu \mathrm{M}$ was estimated, indicating a negligible leaching out from the nanoparticles and /or the presence of residual $\mathrm{Gd}^{3+}$ originating from the synthesis process.

\section{References.}

(1) Lauffer, R. B. Chem. Rev. 1987, 87, 901.

(2) Hanaoka, K.; Kikuchi, K.; Urano, Y.; Narazaki, M.; Yokawa, T.; Sakamoto, S.; Yamaguchi, K.; Nagano, T. Chemistry \& Biology 2002, 9, 1027. 